\title{
A NEW ECO-DRIVING ASSISTANCE SYSTEM FOR A LIGHT VEHICLE : ENERGY MANAGEMENT AND SPEED OPTIMIZATION
}

\author{
Qi Cheng, Lydie Nouvelière and Olivier Orfila
}

\begin{abstract}
This paper presents a new method to model and optimize the vehicle fuel consumption and its speed in the design of an eco-driving assistance system (EDAS) developed within the EU ecoDriver project. The main objective of this EDAS is to combine a precise fuel consumption model with a robust optimization module. An optimal speed profile is obtained to reduce the energy consumption. The gear management is also included in this procedure. The instantaneous fuel consumption rate is expressed as a piecewise polynomial of the instantaneous engine speed and engine torque. A dynamic programming technique is used to optimize the vehicle fuel consumption considering the safety requirements. The real vehicle experiments show the good performance of the piecewise model. The algorithm is implementable in a light vehicle Renault Clio 3 .
\end{abstract}

\section{INTRODUCTION}

The significant and continuing increase of fuel costs leads companies and governments to think about the means to reduce the consumption of energy. In addition, legitimate concerns related to sustainable development and to the satisfaction of the international standards of

This work is supported by the EU FP7 ecoDriver project

Qi Cheng, and Olivier Orfila are with the Laboratoire LIVIC, IFSTTAR, 14, route de la Minière, 78000 Versailles, France, qi.cheng@ifsttar.fr, olivier.orfila@ifsttar.fr

Lydie Nouvelière is with the Laboratoire IBISC EA 4526, CE 1455, 40 Rue du Pelvoux, 91020 Courcouronnes, France and the Laboratoire LIVIC, IFSTTAR, 14 , route de la Minière, 78000 Versailles, France, lydie.nouveliere@ibisc.univ-evry.fr environmental management systems, encourage all vehicle users to travel in an eco-driving way to decrease $\mathrm{CO}_{2}$ emissions.

The safety and the fuel economical efficiency are the first two important issues when the customers decide to buy a new car. Indeed ecodriving can not only bring an economy in money and ecology but it can also minimize the risk of traffic accident (by 10 to $15 \%$ ) by applying a responsible driving. The economical-ecological way of driving (eco-driving) is a citizen driving behavior which allows to reduce the energy consumption up to $15 \%$ and to limit the Greenhouse Effect responsible for the climatic warming.

The principle of the proposed Eco-Driving Assistance System (EDAS) consists in providing an optimal profile sent to the Human-machine interface module on board to advise the driver in real time. This optimal profile is computed by an optimization process on the vehicle energy consumption. The fuel consumption model is the first key point in the design of the EDAS [1] before generating the reference signal to the driver (speed, gear, ...).

In the general case, the vehicle energy consumption model is represented by a simple function of the engine speed, engine torque, engine power, vehicle acceleration and vehicle speed. Here, a piecewise model is applied by considering the engine map as several separated subareas in each of which the fuel consumption is estimated by a single 2-order polynomial function of the engine torque and engine speed. With this technique, the precision of the fuel consumption model can be greatly improved. 
Then, a dynamic programming technique is used to optimize the vehicle energy consumption considering the safety requirements. An optimal profile of the vehicle speed and gear number is hence computed to permit the eco-driving.

The paper is organized as follows. After a brief presentation of the EU ecoDriver project, a schematic diagram of the proposed eco-driving system is given in Section 2. A simple vehicle model is described in Section 3 followed by the details of the vehicle fuel modeling technique in Section 4 . The dynamic programming technique is presented in Section 5. Some experimental results are shown is Section 6 regarding the energy modeling. Some conclusions are given in Section 7.

\section{ECO-DRIVING ASSISTANCE SYSTEM DESIGN}

This work is a part of European project FP 7 ecoDriver.

\section{A. EcoDriver Project}

The project ecoDriver - Supporting the driver in conserving energy and reducing emissions - a EU FP7 project - addresses the need to consider the human element when encouraging green driving, since driver behavior is a critical element in energy efficiency. The focus of the project is to develop an eco-driving technology working with the driver. The project aims to deliver the most effective feedback to drivers on green driving by optimizing the driver-power train-environment feedback loop. It will carry out a substantial programme of work to investigate how to win the maximum support for the driver to obtain the most energy-efficient driving style in terms of energy use.

The project examines driving not only with present and near-term power trains but also with a full range of future vehicles, including various types of hybrid and plug-in electric vehicles. A comprehensive evaluation will be carried out both with driving simulators and in fleets of vehicles. The target of ecoDriver project is to deliver a $20 \%$ improvement in energy efficiency by an autonomous means (without cooperative systems).

\section{B. Power train diagram}

The Figure 1 gives a description of the power train model used in the EDAS. From road and vehicle measured data, optimal speed and gear number profiles are computed and sent to the human-machine interface module to advise the driver.

The aim of the global chain schematic diagram of the full system for the EDAS is to combine safety requirements and fuel consumption reduction by optimizing the vehicle speed and the gear management. It requires information on several measured signals from the vehicle (speed, position, gear number), environment (longitudinal headway spacing), road (legal speed limitation, road geometrical attributes) to obtain such optimal profiles. Hence a power train model that provides the vehicle state vector and the instantaneous fuel consumption model giving the vehicle fuel consumption information has been developed and experimentally validated. An optimization procedure is formulated which suggests an optimal profile in terms of speed and gear number to the driver in order to reduce the fuel consumption considering the road data and the safety requirement.

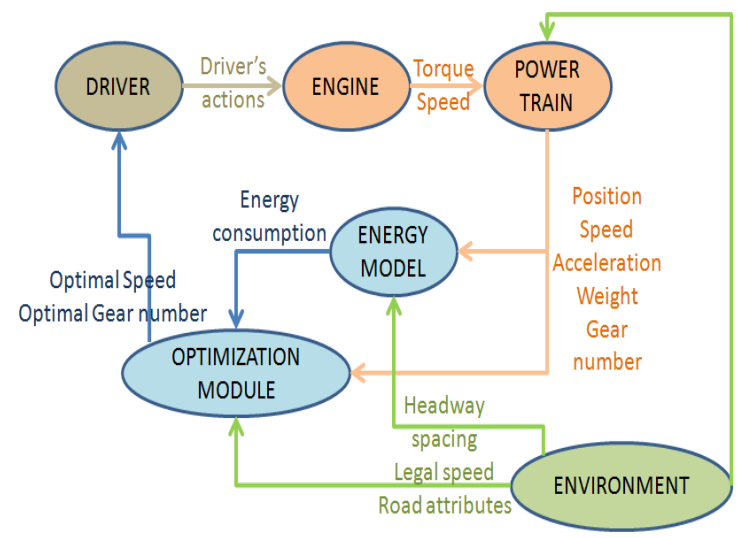

Fig. 1. Schematic diagram of the power train model in the eco-driving system. 


\begin{tabular}{|c|c|}
\hline$v_{x}$ & Vehicle longitudinal speed \\
\hline$r$ & Wheel radius \\
\hline$\eta$ & Total efficiency parameter of transmission \\
\hline$N_{t}$ & Gear ratio \\
\hline$N_{f}$ & Differential ratio \\
\hline$T_{e}$ & Tratal vehicle mass \\
\hline$T_{b}$ & Gravitational constant \\
\hline$M$ & Rolling resistance force \\
\hline$g$ & Air density \\
\hline$f_{R}$ & Area of vehicle front surface \\
\hline$\rho$ & Aerodynamic resistance coefficient \\
\hline$S$ & Road grade \\
\hline$C_{x}$ & Engine rotational inertia \\
\hline$\theta$ & Rotational inertia of the transmission \\
\hline$I_{e}$ & Rotational inertia of the wheels \\
\hline$I_{t}$ & \\
\hline$I_{d}$ &
\end{tabular}

TABLE I

Nomenclature of the POWER train MOdel

\section{VEHICLE MODEL}

The vehicle dynamics model used by the optimization module is as follows ([2])

$$
\begin{gathered}
\dot{v}_{x}=\frac{r^{2}\left(M g f_{R}+0.5 \rho S C_{x} v_{x}^{2}+M g \sin (\theta)\right)}{M r^{2}+I_{e t} N_{f}^{2} N_{t}^{2}+I_{d w}} \\
+\frac{r\left(\eta N_{f} N_{t} T_{e}-T_{b}\right)}{M r^{2}+I_{e t} N_{f}^{2} N_{t}^{2}+I_{d w}}
\end{gathered}
$$

where

$$
\begin{aligned}
I_{e t} & =I_{e}+I_{t}, \\
I_{d w} & =I_{d} N_{f}^{2}+I_{w} .
\end{aligned}
$$

This model gives only the longitudinal part of vehicle dynamics, the one needed for the energy consumption. The designation of the variables is given in Table I. In the Model (1), the influence of the brake torque is ignored. The relationship between the engine speed $\omega_{e}$ and vehicle speed $v_{x}$ is given by

$$
\omega_{e}=\frac{N_{t} N_{f} v_{x}}{2 \pi r} .
$$

\section{Fuel CONSUMPTION MODELING}

The estimation and the prediction of the real fuel consumption play key roles in the eco-driving system. A large literature has been contributed to the modeling of the vehicle fuel consumption [3], [4], [5], [6]. Some new methods to model the vehicle fuel consumption using the engine torque and engine speed are discussed in [7], [1], [8], [9]. It is difficult to know which kind of model is better than the others, since one kind of these models can be converted into the others. A comparison of these models is given in [10].

\section{A. A new piecewise fuel consumption model}

Based on our previous results in [10], [7], [1], [8], a new vehicle instantaneous fuel consumption model is proposed in this section. The innovation of this new model is that a piecewise model is used to describe the non linear relationship among the instantaneous fuel consumption and the engine speed $\omega_{e}$ and engine torque $T_{e}$. According to the real fuel consumption data, it is difficult to compute the fuel consumption rate by a single equation on the whole engine map. However, the engine map could be separated into some sub-areas which can be approximated by a single equation.

In our new energy consumption model, the instantaneous fuel consumption rate $F C$ is cut into several pieces according to the values of the engine speed $\omega_{e}$ and engine torque $T_{e}$, see Figure 2. First, we separate the entire engine map into some sub-areas in which the fuel consumption can be expressed by a single equation; Secondly, the parameters of the fuel consumption model are estimated using the real experiments data in each sub-area in which the vehicle instantaneous consumption rate is expressed by

$$
F C=\sum_{i=0}^{2} \sum_{j=0}^{2} L_{i, j} \omega_{e}^{i} T_{e}^{j} .
$$

The main problem of this modeling technique is to set the number of the sub-areas and find the break point of each sub-area. Generally speaking, the more the number of sub-areas is, the more precise the model is. The break point of each sub-area is detected by a least squares method. The shape of some sub-areas is regular, 
while the one of the others is not (e.g. $F C 10$ in Figure 2).

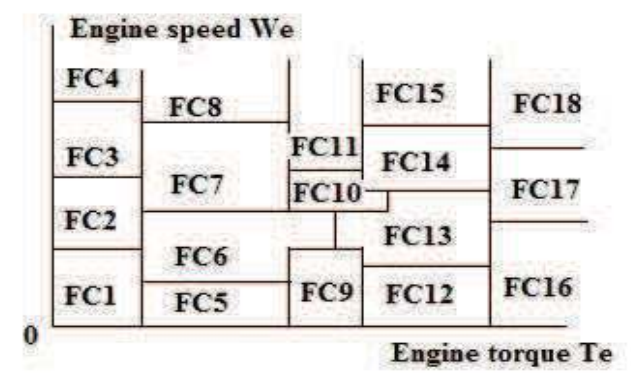

Fig. 2. Sub-area division of the engine map.

\section{Optimization METHOD}

Since the fuel consumption modeled is fixed with its estimated parameters, the longitudinal model given in section 3 can be used in an optimization procedure.

\section{A. Problem formulation}

The problem of the optimal energy consumption is a classic optimal control problem. Firstly, an objective function $J$ should be determined; Then, a method of optimization is chosen to solve this problem. The dynamic programming technique is one of the popular methods to solve this optimization problem [11]. The discrete optimal fuel consumption problem is expressed as

$$
\left\{\begin{array}{l}
\min _{U} \sum_{k=0}^{N} J_{k}\left(X_{k}, U_{k}\right) \\
X_{k+1}=f\left(X_{k}, U_{k}, \theta_{k}\right) \\
X_{k} \in\left[X_{l b k}, X_{u b k}\right] \\
U_{k} \in\left[U_{l b k}, U_{u b k}\right] \\
X(0)=X_{0} \\
X(N)=X_{N},
\end{array}\right.
$$

where $X_{k}=\left[v_{x, k}\right]$ is the vehicle longitudinal speed, $U_{k}$ is the control variable, $\theta_{k}$ is the system parameters, $X_{l b k}$ and $X_{u b k}$ are the lower and upper speed bounds, $U_{l b k}$ and $U_{u b k}$ are the lower and upper bounds of the control variables.

\section{B. Objective function}

The objective function $J$ must be a compromise between the fuel consumption $(F C)$ and the travel time $(T)$ as well as the driver feeling (SMOOTH),

$$
J=Q 1 * F C+Q 2 * T+Q 3 * S M O O T H,
$$

where $S M O O T H$ is computed by

$$
\begin{aligned}
\text { SMOOTH } & =\sum_{k=0}^{K-1}\left(A *\left(\max \left(0, X_{k+1}-X_{k}\right)\right)\right. \\
& \left.+(1-A) * \operatorname{abs}\left(\min \left(0, X_{k+1}-X_{k}\right)\right)\right),
\end{aligned}
$$

where $A$ is a penalty coefficient of the increase speed. It permits not to obtain too much oscillations between hard accelerations and hard braking phases during the trip.

$F C$ is a function of the engine speed $\omega_{e}$ and engine torque $T_{e}$ and it can be expressed by a function of vehicle speed $v_{x}$ by using the vehicle model in Section 3 (Equation 1, 2). The travel time $T$ and the SMOOTH function are also the function of vehicle speed $v_{x}$. In this objective function $J$, each term can be expressed by the vehicle speed $v_{x}$.

\section{Dynamic programming}

Dynamic programming is used widely to solve the optimal control problem. Dynamic programming is based the Bellman's maximum principle [11]. The basis of dynamic programming is a backward iteration. For $k=N-1, N-2 \ldots 0$,

$$
\begin{aligned}
J_{N} & =\zeta_{N}\left(X_{N}\right), \\
J_{k}\left(X_{n}\right) & =\min _{U_{k}}\left(\zeta_{k}\left(X_{k}, U_{k}\right)+J_{k+1}\left(f\left(X_{k}, U_{k}\right)\right)\right) .
\end{aligned}
$$

Using the $J_{k}$, first, we can obtain the optimal control variable $U_{k}$, for $k=0,1, \ldots, N-1$

$$
\hat{U}_{k}=\arg \min _{U_{k}}\left(\zeta_{k}\left(X_{k}, U_{k}\right)+J_{k+1}\left(f\left(X_{k}, U_{k}\right)\right)\right) \text {. }
$$

Then, we can rebuild the optimal trajectories of $X_{k}$ with the initial value $X(0)$ by the following equation,

$$
X_{k+1}=f\left(X_{k}, \hat{U}_{k}, \theta_{k}\right)
$$


Thanks to the dynamic programming technique, an optimal profile of the vehicle speed $v_{x}$ and gear number $N$ is obtained in order to reduce the fuel consumption.

\section{EXPERIMENTAL RESULTS}

\section{A. Test vehicle}

A middle class manual transmission car, the RENAULT Clio 3 equipped with CAN fuel consumption measurements (see Figure 3) is chosen in our experiments as it represents the car of a "man in the street" in France. All the parameters of the power train model and the fuel consumption model are estimated from the real experimental data of the RENAULT Clio 3.

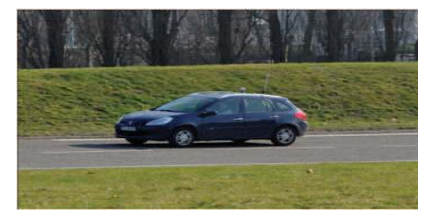

Fig. 3. The test vehicle: RENAULT Clio 3.

\section{B. Experimental validation of the energy model}

To achieve the vehicle dynamics state, some sensors were installed in the test vehicle: longitudinal speed (odometer) and acceleration, engine speed, acceleration pedal and fuel flow meter. The energy consumption is acquired from the CAN Bus channel with a $80 \mathrm{~mm} \cdot{ }^{3}$ resolution. A RTMAPS (CINTEMPORA, France) platform is used to guarantee the real-time data logging phase and registration on board. The experimental plan consisted in travelling on a dedicated route constituted of different road profiles.

The results of one real test are shown in the Figure 4, 5, 6, 7, 8 and 9. The vehicle speed $v$ is shown in Figure 4 in $k m / h$. The road slope and the gear number are shown in Figure 4. The corresponding engine torque and engine speed are shown in Figure 6 and Figure 7, respectively. The instantaneous fuel consumption rate $F C(\mathrm{~mL} / \mathrm{s})$ calculated from Model 3 is shown in Figure 8 compared to the instantaneous fuel consumption rate read from the CAN bus. It is clear that the estimated instantaneous fuel consumption rate (blue line) could track its real value (green line) as a whole. The error occurs when this is a strong brake because the influence of the brake torque is ignored in the Model (1).The cumulated fuel consumption in shown in Figure 9 associated to the results estimated from the Model 3. We can see that the cumulated error of the fuel consumption calculated from our model is not big and the performance of our new piecewise model is confirmed.

Another real test results of the EADS are given in Figure 10. Our prototype car runs under the conditions that there is always another vehicle runs before our car and the speed limit in this trip is known. We set $Q 1=Q 2=Q 3=1$ and $A=0.4$ in the objective function $J$. The preceding vehicle speed is given in blue dash-dot line. The optimal speed profile given by our new methods is presented in red line. The method developed in [8] is displayed in violet dash line as a reference. It is clear that our new profile is better the the old one since it avoids the frequent accelerations and decelerations. The total fuel consumption is saved by $20 \%$ with our new profile.

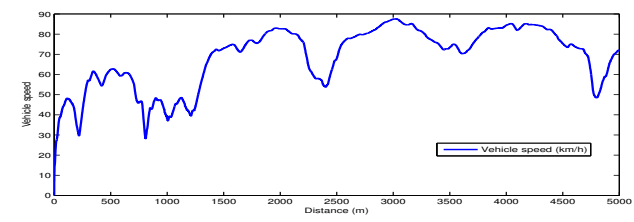

Fig. 4. Vehicle speed.

\section{Conclusions}

An innovative fuel consumption modeling technique is proposed in this paper in order to develop an eco-driving assistance system. The vehicle fuel consumption is estimated by a piecewise polynomial of the instantaneous engine speed and the instantaneous engine torque. The accuracy of the model is improved through piecewise modeling technique. The key issues of this new fuel consumption model is to find the break points of each sub-model. 


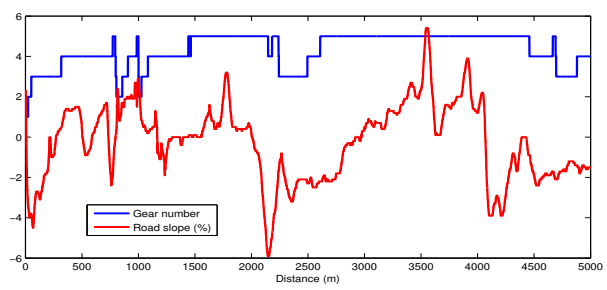

Fig. 5. The road slope and gear number

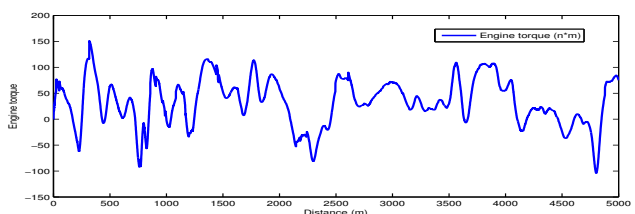

Fig. 6. Engine torque.

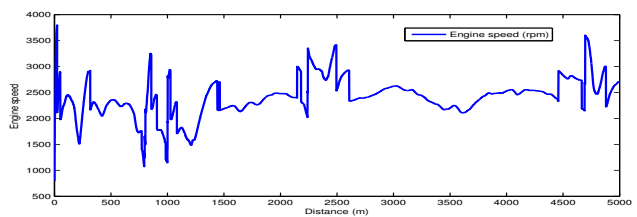

Fig. 7. Engine speed.

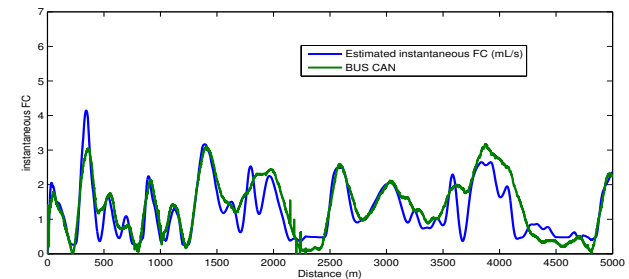

Fig. 8. Instantaneous fuel consumption rate $F C$.

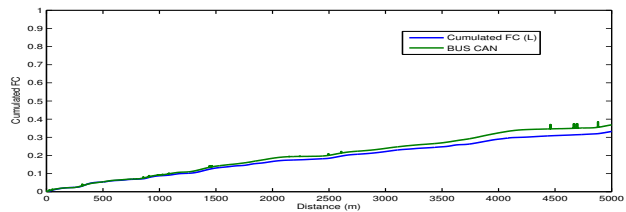

Fig. 9. Cumulated fuel consumption.

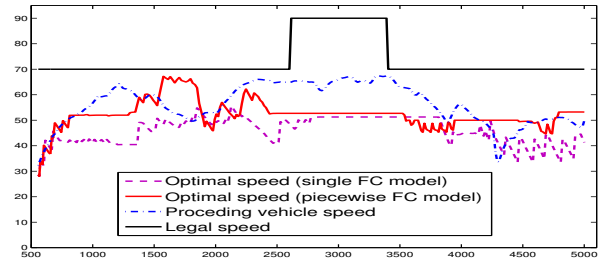

Fig. 10. Optimal profile.

\section{REFERENCES}

[1] H. T. Luu, L. Nouvelière, V. Hoarau, and S. Mammar, "Vehicle speed control for a safety-economicalecological compromise: Development of a driver assistance system," in 10th International Symposium on Advanced Vehicle Control, Loughborough, UK, 2010.

[2] T. Gillespie, Fundamentals of vehicle dynamics. Warrendale, PA: Society of Automotive Engineers, 1992.

[3] R. Akcelik and C. Bayley, Some results on fuel consumption modles. Australian Road Research Board, 1983, pp. 51-56.

[4] K. Post, J. Kent, J. Tomlin, and N. Carruthers, "Fuel consumption and emission modeling by power demand and a comparison with other models," Transport Research A, vol. 18, no. 3, pp. 191-213, 1984.

[5] Y. Wong, Theory of Ground Vehicle. Chichester, USA: Wiley, 2001.

[6] K. Ahn, H. Rakha, A. Trani, and M. Van Aerde, "Estimating vehicle fuel consumption and emissions based on instantaneous speed and acceleration levels," Journal of Transportation Engineering, vol. 128, pp. 182-190, 2002.

[7] H. T. Luu, L. Nouvelière, and S. Mammar, "Dynamic programming for fuel consumption optimization on light vehicle," in 6th IFAC Symposium Advances in Automotive Control, Munich, Germany, 2010.

[8] — , "Ecological and safe driving assistance system: design and strategy," in IEEE Intelligent Vehicles Symposium, San Diego, USA, 2010.

[9] B. Saerens, M. Diehl, and E. Van den Bulck, Optimal Control Using Pontryagin's Maaximum Principle and Dynamic Programming. Springer, 2010, pp. $119-138$

[10] H. T. Luu, L. Nouvelière, and S. Mammar, "Modélisation de la consommation en carburant d'un véhicule léger à partir de données expérimentales," in Jonrnée national MACS, Angers, France, 2009.

[11] R. Bellman, Dynamic programming. Princeton, NJ: Princeton University Press, 1957. 